\title{
O ESTEREÓTIPO DO HOMOSSEXUAL EM PROFESSORES(AS) DE CIÊNCIAS
}

\author{
Mônica Ismerim Barreto ${ }^{1}$ \\ Maria Inêz Oliveira Araújo ${ }^{2}$
}

\section{RESUMO}

Acredita-se que comportamentos masculinos sejam diametralmente opostos dos femininos. Dessa forma, espera-se que homens sejam agressivos e mulheres delicadas. Quando homens têm comportamentos delicados e mulheres são agressivas as normas invisíveis de gênero são contestadas. E as pessoas que se atreveram a não seguir essas normas são taxadas de homossexuais. Assim, tanto homossexuais quanto aqueles que são identificados como tal, por não seguirem os papéis considerados como válidos para o masculino ou feminino, sofrem preconceito e a discriminação. Existe uma verdadeira 'ditadura de gênero' na qual, os que se desviam da norma são mal vistos. Acredita-se que determinados comportamentos são exclusivos de homens e que esses diferem daqueles esperados para as mulheres. Na escola, alunos e alunas que apresentem comportamentos diferentes do padrão esperado são estigmatizados e agredidos. E essa discriminação pode surgir inclusive de professores. Na escola, é o professor de Ciências que é considerado aquele que tem o 'saber competente' para discutir temas ligados à sexualidade. Porém, este não tem, muitas vezes, esse tema contemplado na sua formação e termina por discuti-lo a partir do senso comum. Esse trabalho teve como objetivo identificar se professores e professoras de Ciências das escolas municipais de Aracaju/SE que participam do programa de formação continuada "Horas de Estudo" acreditam ser possível identificar tendências homossexuais em alunos. Para tanto, um questionário anônimo, constituído por questões abertas e fechadas foi respondido por oito professoras e um professor. Nesse trabalho discutiremos apenas uma questão que trata da possibilidade de identificação de tendências homossexuais em alunos. Evidenciamos que o grupo pesquisado, na sua maioria, acredita ser possível tal identificação. Os resultados mostram que mais da metade dos professores do grupo pesquisado faz essa identificação baseada na ideia que homens e mulheres possuem comportamentos diferentes e que os homossexuais são indivíduos que tem comportamentos do sexo oposto ao seu. Essa forma de identificação estereotipada dos homossexuais indica que para esses educadores (as) existem comportamentos próprios 'para menino' e 'para menina'. Aqueles alunos que apresentam outra forma de se comportar vão ser identificados como homossexuais.

Palavras-chave: Ensino de Ciências. Estereótipo. Homossexualidade.

\footnotetext{
${ }^{1}$ Mestre em Educação pela Universidade Federal de Sergipe. Professora das redes estadual e municipal de ensino em Sergipe. Email: monicaibarreto@ yahoo.com.br ${ }^{2}$ Coordenadora do Programa de Pós-graduação em Educação da Universidade Federal de Sergipe. Email: inez@ufs.br
} 


\section{ABSTRACT}

It is believed that male behaviors should be different from the female ones. Thus, it is expected that men are aggressive and women are sensitive. When men have sensitive behaviors and women are aggressive, the invisible gender norms are challenged. And people who dare not to follow these rules are labeled as homosexuals. So, both homosexuals and those who are identified this way, suffer prejudice and discrimination for not playing the rule considered valid for male or female. There is a real 'gender dictatorship' in which those who do not follow the rules are perceived negatively. It is believed that certain behaviors are intrinsic to men and that they differ from those expected for women. At school, students who have behaviors different from the expected pattern are stigmatized and abused. And such discrimination can come even from teachers. At school, the science teacher is considered the professional who has the 'competent knowledge' to discuss issues related to sexuality. However, such issue is not contemplated in their training and they end up by discussing it in a general way. This study aimed to identify whether science teachers, that work in municipal schools in Aracaju/SE and that participate in the program "Horas de Estudo", believe it is possible to identify homosexual tendencies in students. For this, an anonymous questionnaire, consisting of subjective and objective questions, was answered by eight female teachers and a male one. In this paper we will discuss only one question, which deals with possibility of identifying homosexual tendencies in students. We show that most of the participants believe that such identification is possible. The results show that more than half of the surveyed teachers make this identification based on the idea that men and women have different behaviors and that homosexuals are individuals who behave the opposite way concerning to their gender. This form of stereotyped identification of homosexuals indicates that for these educators there are behaviors that are specific 'for boys' and others 'for girls'. Those students who have a different way to behave will be identified as homosexual.

Keywords: Science Teaching. Stereotype. Homosexuality. 


\section{Introdução}

O que significa 'ser homem' e 'ser mulher' no início do século XXI? Após a revolução sexual, na década de 60 do século passado, onde as mulheres lutaram por igualdade de direitos e oportunidades, quebraram barreiras e passaram a competir com os homens inclusive conquistando espaços antes redutos masculinos, como o futebol, a idéia que a mulher não poderia ocupar espaços públicos passou a ser questionada. Alguns desses espaços ainda estão sendo duramente conquistados. O preconceito contra a jogadora de futebol continua existindo, mas como assinala Franzini (2005, p. 315) tem se observado uma

rápida e impressionante expansão desse esporte entre as mulheres, mundialmente registrada a partir da década de 198. Basta notar que a própria criação da versão feminina da Copa do Mundo é fruto desse processo de organização e institucionalização, que em alguns países criou uma estrutura equiparável, quando não superior, à do futebol masculino, como na China e nos Estados Unidos, para citar dois dos casos mais significativos.

De acordo com Negrini (2006) foi Pierre Cardin que, na década de 60 do século XX, lançou as camisas coloridas para o público masculino. Como assinala esse autor "Dessa época em diante, a moda masculina nunca mais foi à mesma." (NEGRINI, 2006 p. 32) No final do século XX, início do XXI, ocorre uma transgressão de gêneros, com o surgimento de uma nova imagem de homem - aquele que "se preocupava em se vestir bem, gostava de cozinhar e ir as compras. Atividades como ir ao salão de beleza, clínica de estética, dançar ou até cuidar das crianças não ameaçavam de forma alguma, sua masculinidade." (NEGRINI, 2006 p. 35-36).

Porém, como assinala Pollack (1999), para crianças e adolescentes, o 'Código dos meninos' ainda se faz presente, reforçando os comportamentos adequados para meninos. Ser forte, não chorar, não demonstrar seus sentimentos, ou qualquer outra atitude considerada 'feminina' são punidos de forma vigorosa pelos companheiros. Como ressalta esse autor, esse engessamento de padrões comportamentais, gera problemas graves nos meninos, que refletem inclusive na idade adulta. 
Existem ainda comportamentos e objetos que estão associados ao masculino ou feminino. Quando um menino brinca com um objeto considerado 'de menina' vai receber admoestação de adultos e outras crianças para que se adeque ao padrão masculino vigente. Com a menina é semelhante. Ela é ensinada a gostar de determinadas cores e rejeitar atitudes violentas.

Blaise (2005, apud PAECHTER, 2009) indica que "os meninos não tem permissão de brincar com bonecas Barbies" (2005, p. 120 apud PAECHTER, 2009 p.73). Paetcher assinala ainda que a publicidade de brinquedos é feita por uma perspectiva de gênero, na qual para os meninos são apresentados brinquedos que envolvam atividades físicas, enquanto que para as meninas, são oferecidas bonecas e utensílios domésticos.

Segundo Caldas-Coulthard e Van Leeuwen (2000), crianças de ambos os sexos poderiam brincar tanto com bonecos como a "Barbie" ou "Ken" (bonecos vistos como 'de meninas') como com "Jacqueline" ou "The Rock" (lutadores que tem características atribuídas ao masculino). Porém, como os autores ressaltam, "meninos tendem a não brincar com Ken; meninas tendem a não brincar com Jacqueline". (p.13).

Para Sarat e Campos (2008), esse modelo dicotômico de sexualidade, onde ocorre a determinação da forma de agir e comportar a partir de uma divisão entre meninos e meninas é, na realidade, uma forma de reforçar o modelo heterossexual vigente. Tal atitude faz com que as diferentes identidades sexuais não sejam discutidas e os papéis determinados culturalmente para cada sexo sejam vistos como naturais.

\footnotetext{
Assim, meninos e meninas são tratados prioritariamente, por uma referência biológica, na qual seus aparelhos genitais definem sua orientação sexual caracterizada por uma cultura binária e dividida que enfatiza para os meninos brincadeiras como carrinhos, máquinas, jogos, atividades que remetem à vida pública e fora do âmbito doméstico. As meninas ficam sujeitas as atividades com boneca, miniaturas de móveis, fogão, panelas, casinhas, que remetem à vida privada e ao espaço doméstico, contrariando frontalmente uma organização social na qual a mulher, cada vez mais, ocupa espaços públicos (SARAT; CAMPOS, 2008, p.4)
} 
Como aponta Leda Costa (2006) os homens são criados desde cedo em contato com a bola, tanto que é considerado no mínimo estranho, o menino que não tem interesse por futebol. Um episódio real é relatado por Andrew Sullivan: quando tinha aproximadamente 10 anos, uma menina perguntou "Você tem certeza que aí em baixo você não é menina?" (SULLIVAN,1996, p.12). O motivo da pergunta - ele não gostava de jogar futebol. Não gostar de um determinado esporte seria assim, suficiente para que ele não fosse reconhecido como 'menino'. Não havia uma conotação afetivo-sexual para a pergunta, apenas não fazer algo que é entendido como 'coisa de menino'.

Para essa autora, está ocorrendo uma mudança na ideia que "futebol é coisa de menino", pois tal afirmativa não resiste a uma análise mais cuidadosa, quando observa-se mulheres jogando futebol como profissionais ou em momentos de lazer, e discutindo futebol em mesas redondas sobre o tema na televisão.

Porém, segundo Goellner (2005) existe um estranhamento aos corpos femininos que tem sua aparência corporal é excessivamente transformada pelo exercício físico e pelo treinamento contínuo. Essas são consideradas "características viris que não apenas questionam sua feminilidade, mas também colocam em dúvida a autenticidade do seu sexo." (p.148). Tal fato é corroborado por Cardoso (2000), que relata em uma reportagem sobre a ameaça feminina à supremacia dos homens no esporte, a indignação da atacante Sissi, da seleção brasileira de futebol feminino quando é questionada se tem namorado. Esse fato este aponta a suspeição que mulheres que jogam futebol - um esporte predominantemente masculino - poderiam não ser heterossexuais.

Nessa mesma reportagem de Cardoso, ele cita um artigo da tenista Martina Navratilova, no qual ela "demonstrava sua irritação com a diferença de tratamento. 'Se um grande tenista homem chorar na quadra, será descrito como histérico ou se dirá que ele está num de seus maus dias?', perguntou Martina. 'Por que sempre que um jogador atua mal se diz que ele 'jogou como uma moça'? Por que toda mulher atleta é vista como homossexual e todo homem atleta é presumidamente heterossexual?'." (CARDOSO, 2000 p. 21)

Podemos observar, assim, que atividades consideradas mais agressivas são vistas como 'espaços privados' de indivíduos do sexo masculino. Quando estas atividades são realizadas com eficiência pelas mulheres, 
a feminilidade destas é colocada em xeque. Como se uma mulher 'de verdade' não pudesse realizar tal atividade, ou se a realização de uma atividade 'masculina' por mulheres diminuísse a masculinidade dos homens

Desde pequenos, crianças aprendem que existem comportamentos e brincadeiras próprios para cada sexo. Porém, como ressalta Daniela Finco (2003) após observar crianças de 4 a 6 anos brincando em uma instituição infantil

meninos e meninas se revezam nos papéis, sem menosprezar ou desprezar papéis considerados masculinos ou femininos; [...] As crianças brincam espontaneamente com os brinquedos que escolhem sem constrangimentos. Meninos participavam de brincadeiras como cuidar da casa, cozinhar, passar roupa, cuidar dos filhos, que são vistas como funções das mulheres; assim as crianças trocavam e experimentavam os papéis considerados masculinos ou femininos durante os momentos de brincadeira (FINCO, 2003 ,p. 94).

Essa autora levanta a hipótese que

as crianças ainda não possuem práticas sexistas em suas brincadeiras e, portanto, não reproduzem o sexismo presente no mundo adulto. [...] ao observar as relações entre as crianças, foi possível levantar a hipótese de que os estereótipos dos papéis sexuais, os comportamentos pré-determinados, os preconceitos e discriminações são construções culturais, que existem nas relações dos adultos, mas ainda não conseguiram contaminar totalmente a cultura da criança (FINCO, 2003 p. 95).

Souza e Rodrigues (2002), observaram fato semelhante para crianças de 8 e 9 anos. Estas, quando estavam brincando geralmente se envolviam com as atividades sem preocupação com a adequação das mesmas ao seu gênero. Meninos e meninas brincavam de "rebater bola, encenar 'Os escravos de Jó' e brincar de jogo da velha” (p. 495) sem qualquer preconceito de cunho sexual

Dessa forma, concordamos com Daniela Finco, quando diz que "são os adultos que esperam que as meninas sejam de um jeito e os meninos de outro" (FINCO, 2003 p. 95). Enquanto as crianças ainda não interiorizaram os comportamentos considerados adequados para cada sexo, transitam entre as brincadeiras sem a preocupação do reconhecimento do seu sexo pelo outro. 
Para Carrie Paechter (2009), meninos e meninas vão aprender a 'ser homem' e 'ser mulher' em "comunidades de prática ${ }^{3}$ de masculinidade e feminidade" (p.16). Desde que o bebê é nomeado como menino ou menina, "ele entra em uma constelação de comunidades locais superpostos de prática de masculinidade e feminidade, na qual aprenderá com os membros estabelecidos no grupo (pais e irmãos) o que significa ser homem ou mulher em determinada comunidade" (p.17). Dessa forma, nas comunidades de prática, meninas e mulheres "constroem uma espécie de um tipo ideal (ou diferentes tipos, em comunidades diversas) do que significa ser mulher (feminidade) e, ao mesmo tempo, desenvolvem a compreensão de quem elas são (sua feminidade individual e grupal) em relação a esse tipo.” (p.22). A masculinidade, de forma semelhante, também é "mais um tipo ideal que inscreve o que se espera que homens típicos pensem e façam." (p.23). Homens e mulheres são assim construídos dentro dos modelos que cada comunidade acredita ser característica do masculino e feminino. Um indivíduo para ser aceito como "plenamente masculino" em determinado grupo social, precisa manifestar comportamentos e características que possibilitem seu reconhecimento como tal pelos demais membros. (PAECHTER, 2009).

Isso nos leva a um questionamento - o que levaria as pessoas a identificarem alguns indivíduos como homossexuais e outros não? Sullivan relata que procurou algo que o diferenciasse dos outros meninos, uma evidência física, ou comportamental. Mas não percebeu nada de diferente. Ele conta que gostava de ficar "zanzando com eles [os meninos] pelos bosques da redondeza, formando clubes secretos, brincando de pegador (e, em boa parte de tudo isso, creio que eu era indistinguível de qualquer outro menino)" (SULLIVAN, 1996, p.15). Ou seja, ele era "praticamente normal" (SULLIVAN, 1996, p.16).

Assim, permanece a dúvida - porque alguns indivíduos são nomeados de homossexuais (mesmo sem o ser) e outros não (podendo ser). O que está na realidade por trás dessa identificação? Luiz Mott nos dá uma pista em sua crônica "Os gays e os homens delicados" quando assinala que a maioria das pessoas associa atitudes delicadas em homens à homossexualidade. Mott diz que não essa associação delicadeza/homossexualidade em homens é um engano, que jeitos

${ }^{3}$ Segundo Paechter (2009 p. 16) "uma comunidade de prática é, em um sentido bem simples, uma comunidade em que seus membros se engajam em uma prática compartilhada". 
efeminados em homens não são sinônimos de homossexualidade (MOTT, [sd]).

Mott identifica a confusão que se faz entre os comportamentos esperados (e que são determinados socialmente para o masculino e o feminino) com a orientação sexual (homo, bi ou heterossexual).

Dessa forma, tanto homossexuais quanto aqueles que são identificados como tal, por não seguirem os papéis considerados como válidos para o masculino ou feminino sofrem com o preconceito e a discriminação. Existe uma verdadeira 'ditadura de gênero' na qual os que se desviam da norma, do socialmente aceito, são mal vistos.

Acredita-se que determinados comportamentos são exclusivos de homens e que esses diferem daqueles esperados para as mulheres. Dessa forma, aqueles que não se enquadram nos padrões de comportamento esperados para seu sexo biológico, são vistos como 'excêntricos', como nos indica Louro (2005). Existiria "apenas um modo adequado, legítimo, normal de masculinidade e de feminilidade e uma única forma sadia e normal de sexualidade, a heterossexualidade; afastar-se desse padrão significa buscar o desvio, sair do centro, tornar-se excêntrico." (LOURO, 2005, p. 43-44).

Não apresentar comportamento em conformidade com o sexo biológico, é percebido como uma das atitudes mais passíveis de exprobração, dentre aquelas desviantes da norma. Mas não apenas homossexuais são vítimas desse tipo de preconceito. Todos os que não se encaixam nos modelos de comportamento esperados para seu sexo biológico, ou seja menino mais delicado ou menina sem vaidades, são percebidos como 'desviantes' do padrão.

Em uma reportagem, dois adolescentes heterossexuais descrevem as agressões a que são submetidos pelo fato de não exibirem o comportamento considerado adequado para seu sexo:

O estudante Manoel Braga, 18, é heterossexual, mas desde os 12 anos é confundido com gay. O motivo? "Nunca hesitei em pedir um abraço a um colega ou dizer que ele ou ela era muito importante pra mim. A maioria das pessoas vive de acordo com um padrão de coisas que se pode ou não fazer, em vez de fazer simplesmente aquilo que as faz bem", diz. Visivelmente revoltado com a situação, o estudante diz já ter escutado frases extremamente discriminatórias como "você não é dos nossos" e "você não gosta da fruta". 
$[\ldots]$

O professor de inglês Yuki Fujita, 19, sofre com o mesmo problema de Manoel. Yuki começou a ser confundido com gay desde que adotou um estilo diferente do que as pessoas estão acostumadas. [...] Quando está em público, é comum o professor de inglês escutar palavras pejorativas como "viado" (TAMANAHA, 2008, p.1).

São jovens que sofrem com a discriminação pelo fato de não se adequarem aos comportamentos socialmente esperados para seu sexo. A agressão existe pelo fato destes apresentarem comportamentos e atitudes que são considerados como característicos de indivíduos do sexo oposto.

Sobre o sexismo e a homofobia no ambiente escolar, Junqueira indica que estes:

produzem sofrimento e injustiça, uma vez que o preconceito tanto racial como homossexual - afeta as relações sociais, pedagógicas, fatores de marginalização e exclusão de indivíduos. Colocam também em risco o direito à educação, por isso a escola não pode deixar de educar as crianças para o mundo (CONFEDERAÇÃO NACIONAL DOS TRABALHADORES EM EDUCAÇÃO, 2008, p.1).

A educação tem, portanto, um papel importante na busca do respeito e aceitação da diversidade. Uma educação que prima pela diversidade não é excludente, não segrega, nem discrimina. Para que essa educação ocorra é necessário que professores e professoras reconheçam os campos preconceituosos de suas ações e a necessidade de uma construção de visão de mundo não excludente para poder atuar junto a essas diversidades. Devem desfazer estereótipos e mitos sobre os diversos. Compreender porque estes foram assim nominados, e perceber a riqueza que trazem para a escola.

Temas ligados à sexualidade nunca foram tranquilos de serem compreendidos ou abordados, mesmo por aqueles que se interessam pelo assunto. Para professores e professoras, isso não é uma exceção. Os cursos de formação de professores, em sua quase totalidade, não abordam esse tema (FURLANI, 2003). E se a escola tem problemas no trato com temas ligados à sexualidade, quando o tema é 'homossexualidade' a polêmica é ainda maior.

Mas quem são esses professores e professoras que tratam de temas ligados à sexualidade em sala de aula? Castro, Abramovay e Silva 
(2004) indicam que a sexualidade vem sendo tratada principalmente como "um conteúdo restrito ao campo disciplinar da biologia". (p. 38) É o professor de Ciências que vai ser considerado o responsável pela discussão do tema, é ele que vai estar de posse do que estas autoras chamam de "saber competente" (p.38).

Considerando que esses professores e professoras estarão na escola com alunos e alunas que podem ser percebidos como homossexuais e, consequentemente, sujeitos às práticas homofóbicas, surge o problema central desse artigo, que compõe a dissertação de mestrado de uma das autoras desse trabalho: professores e professoras de Ciências do Município de Aracaju, que participam das 'Horas de Estudo" acreditam ser possível identificar tendências homossexuais em alunos?

É necessário, portanto, que se realize uma investigação para conhecer se estes professores e professoras acreditam existir padrões de comportamento identificados como masculinos ou femininos.

Assim, essa pesquisa tem como objetivo identificar se professores e professoras de Ciências das escolas municipais de Aracaju/SE que participam do programa "Horas de Estudo" acreditam ser possível identificar tendências homossexuais em alunos.

Para atingir esse objetivo inicialmente apresentamos uma revisão bibliográfica sobre a forma como os gêneros foram construídos historicamente, passando do modelo do sexo único para o dos dois sexos e de que forma essa mudança favoreceu o surgimento de um padrão para os comportamentos masculinos e femininos, propiciando o surgimento do estereótipo do homossexual.

Nesse trabalho utilizamos a metodologia qualitativa, pois ela é a que nos proporciona melhores condições de atingir o objetivo proposto na pesquisa.

De acordo com Minayo (2007, p. 21), a abordagem qualitativa da pesquisa,

responde a questões particulares. Ela se ocupa, nas Ciências Sociais, com um nível de realidade que não pode ou não deveria ser quantificado. Ou seja, ela trabalha com o universo dos

\footnotetext{
${ }^{4}$ Programa de formação continuada oferecido pela Secretaria Municipal de Educação de Aracaju.
} 
significados, das motivações, das aspirações, das crenças, dos valores e das atitudes. (2007, p. 21)

Considerando que a pesquisa pretende investigar opiniões e atitudes dos(as) professores e professoras, optamos pelo questionário anônimo como instrumento de coleta de dados pelo fato de trabalharmos com um tema polêmico que, em uma entrevista, poderia gerar constrangimentos aos pesquisados no momento da exposição oral e presencial de opiniões e valores muitas vezes fundamentados em preconceitos. O receio do juízo de valor que o pesquisador pudesse fazer no momento da entrevista, poderia levar o pesquisado a falar o que julgava ser politicamente mais correto. Assim, a opção pelo questionário anônimo poderia minimizar esse constrangimento, pois conforme indica Richardson (1999 p. 205) "no caso do questionário anônimo (que não inclui o nome do entrevistado) as pessoas podem sentir-se com maior liberdade para expressar suas opiniões." Como forma de garantir o anonimato os questionários receberam uma numeração, que foi utilizada na análise destes.

Para elaboração do instrumento de coleta, tomamos como base o questionário utilizado por Forastieri (2004) na sua pesquisa sobre as "Concepções de Professores de Biologia do Ensino médio público estadual de Salvador sobre a variedade das orientações sexuais”.

Após a análise e adaptação do questionário a nossa realidade, o mesmo foi validado. As sugestões apresentadas na validação foram acatadas, e o questionário modificado, ficou em sua versão final organizada em duas partes: uma inicial que forneceu os dados gerais e profissionais dos professores para caracterizar o grupo estudado, e uma segunda parte na qual se encontram as questões que enfocam os objetivos da pesquisa. Neste trabalho iremos analisar apenas uma questão: "Você acredita que é possível identificar tendências homossexuais em alunos? Caso a resposta seja afirmativa, como essa identificação poderia ser feita?"

A pesquisa foi realizada com oito professoras e um professor de Ciências do município de Aracaju que trabalham com o $8^{\circ}$ ano, e participam do programa "Horas de Estudo" da Secretaria Municipal de Aracaju. Os professores participantes dessa pesquisa são graduados em Licenciatura em Ciências Biológicas pela Universidade Federal de Sergipe, estão no exercício da profissão há mais de 10 anos e têm entre 34 e 61 anos. 
Esse artigo apresenta uma revisão bibliográfica sobre a forma como os gêneros foram construídos historicamente, passando do modelo do sexo único para o dos dois sexos e como essa mudança engessou os comportamentos masculinos e femininos, propiciando o surgimento do estereótipo do homossexual.

Os resultados mostram que mais da metade do grupo pesquisado acredita ser possível identificar "tendências homossexuais" em alunos e alunas. Para tanto valem-se de estereótipos de comportamento homossexual.

\section{Revisão bibliográfica}

Como diz Montesquieu, filósofo francês que viveu no século XVIII, "parece [...] que sempre julgamos as coisas por uma secreta projeção de nós mesmos" (MONTESQUIEU, 1991 p.104). Tomamos a nós mesmos como fiel da balança para julgar e avaliar o comportamento e as atitudes dos demais seres humanos. É baseado em nossos valores, naquilo que acreditamos ser 'bom' ou 'mal', 'certo' ou 'errado', e que aprendemos como 'corretos' que vamos analisar a nós e aos outros. Aqueles que diferem do que consideramos 'correto', são mal vistos.

Mas como são formados esses valores? No contato com outros seres humanos. É no contato com o outro que nos educamos, como indica Freire (1987). É através desse contato que vamos aprendendo e formando nossos conceitos e valores, a partir dos quais iremos nos avaliar e julgar, além de estender tais apreciações aos outros. Ao entramos em contato com outros seres humanos, que fazem parte do nosso grupo social, aprendemos a identificar sinais, atitudes e códigos reconhecidos como dentro ou fora da norma, do aceito.

Esses códigos, sinais e atitudes produzem referências que "fazem sentido no interior da cultura e que definem (pelo menos momentaneamente) quem é o sujeito." (LOURO, 2008, p. 83). Eles

produzem marcas que propiciam o reconhecimento do indivíduo como pertencente ou não a determinados grupos.

Assim, é a cultura quem vai indicar quais símbolos serão reconhecidos como pertencentes ao masculino ou ao feminino. Como diz Louro: 
A inscrição dos gêneros — feminino ou masculino — nos corpos é feita, sempre, no contexto de uma determinada cultura e, portanto, com as marcas dessa cultura. As possibilidades da sexualidade - das formas de expressar os desejos e prazeres também são sempre socialmente estabelecidas e codificadas. As identidades de gênero e sexuais são, portanto, compostas e definidas por relações sociais, elas são moldadas pelas redes de poder de uma sociedade. (LOURO, 2001, p. 11)

Existe todo um aparato para conformar os indivíduos a um modo masculino ou feminino de vivenciar a sexualidade. Nosso grupo social (família, escola, amigos, religião, leis mídia, médicos) emprega recursos múltiplos e repetitivos para "garantir a coerência e a permanência da norma” (LOURO, 2008, p. 82).

Dessa forma, a chegada de um novo bebê é um evento cercado de expectativas. Desde que a mulher engravida, ela e toda a família começam a pensar nesse embrião como um ser sexuado. Nomes são escolhidos para menina ou menino, as cores que vão predominar no enxoval vão depender do sexo biológico do futuro bebê. Assim, quando essa criança nasce já traz consigo muitas expectativas quanto aos comportamentos que deve apresentar apenas pelo fato de ter pênis ou vulva.

Se esse bebê é um menino, seus presentes vão ser prioritariamente uma bola ou carrinhos, se menina, vai ganhar bonecas e panelas. Toda uma gama de dispositivos vai ser acionada desde antes do nascimento e principalmente depois para 'conformar' esse novo ser ao seu papel sexual, para aquilo que a sociedade, e em especial a família, acredita ser 'natural' para o sexo masculino ou feminino. Aprendemos assim, no contato com o Outro, a 'ser homem' ou 'ser mulher'.

Na escola não é diferente. Ruela et al (2012) ao discorrer sobre um curso de formação de professores sobre gênero e diversidades relata a preocupação dos/as cursistas em limitar a expressão das crianças desde a creche, em ações como "ensinar os meninos a fazerem xixi em pé; incentivar determinações de cores para ambos os gêneros; proibir qualquer ação considerada fora dos padrões do ser masculino ou do ser feminino: não permitir certas roupas de fantasias que denotem o sexo oposto" (RUELA et al, 2012 p. 51). Romper os limites impostos para cada gênero pode ser visto como um problema, principalmente para os meninos, pois 
surge a problemática da homossexualidade, que aparece envolta em preconceitos não só por parte dos profissionais da escola, mas também por parte da família que, muitas vezes, exige providencias da escola; afinal, no seu entender, caberia à instituição a responsabilidade de educar seus filhos e filhas para serem homens e mulheres heterossexuais (RUELA et al, 2012 p. 53-54).

Os comportamentos que são determinados para cada gênero acabam por ser entendidos como algo 'natural' para homens ou mulheres. Aqueles que saírem da norma não serão reconhecidos como 'homens ou mulheres de verdade'. Porém, observando como a sexualidade foi e é entendida por outros povos e ao longo do tempo, fica evidente que não existe um padrão único de viver a sexualidade que seja característico do masculino ou feminino.

Como indica Maria Helena Cruz (2005a), o conceito de gênero, diferente do de sexo, é socialmente construído e ultrapassa as fronteiras do sexo biológico. Essa autora, ao pesquisar sobre as relações de gênero em uma indústria têxtil, identificou essa 'naturalização' de tarefas para cada sexo. Segundo ela:

As tarefas pesadas e insalubres são associadas aos homens e aquelas que exigem cuidados são associadas às mulheres. A formação dos homens é associada a imagens de masculinidade, ao uso da técnica e da força física, enquanto a formação das mulheres aparece sempre relacionada a imagens de feminilidade.

As diferentes obrigações atribuídas aos homens e mulheres em um lugar, a concepção de que as mulheres são aptas somente para alguns tipos e turnos de trabalho, são práticas estruturadas no ciclo da vida de homens e mulheres como algo dado ou naturalizado e não como resultado de construções sociais (CRUZ, 2005b p.18).

Porém, essa 'naturalização' dos papéis sexuais não é um dado 'natural'. Charbel El-Hani (1995), ao discorrer sobre uma reportagem que trata da diferença entre homens e mulheres, na qual são apresentadas apenas duas explicações (biológica ou psicológica) aparentemente excludentes, ressalta que as jornalistas apoiam-se

em alguns resultados obtidos por pesquisadores americanos, mas estes não indicam uma determinação biológica das diferenças entre homens e mulheres, mas apenas que deve existir uma contribuição da biologia para tais diferenças, de modo que elas não poderiam ser explicadas apenas por fatores de ordem histórica e sócio-cultural (El-Hani, 1995, p.20). 
Para esse autor, "a grande maioria das características humanas, em especial aquelas de caráter comportamental, são decorrentes de uma interação entre as estruturas biológicas e o ambiente físico e sociocultural" (EL-HANI, 1995, p.20). Salienta ainda que "a ideia de que o comportamento e a cognição são determinados de forma absoluta pela estrutura biológica e, em última análise, pelo patrimônio genético, tem implicações éticas e políticas significativas" (P.96).

Dessa forma, ao se 'naturalizar' determinados comportamentos, apontando-os como pertencentes a determinado sexo, ignora-se a influência do ambiente e da cultura sobre os indivíduos.

Trevisan (1986), ao entrevistar um funcionário da Fundação Nacional do Índio (FUNAI) que vivia entre os índios Kraô, relata que segundo este, a delicadeza e a afetividade são características dos homens dessa tribo. Para esses índios, a valentia "é uma característica negativa da personalidade" (p.96). O funcionário relata ainda que é muito comum entre jovens solteiros a prática de "fazer cunin", descrito por um jovem índio como "eu ponho na sua bunda e depois você põe na minha" (p.97). Para esses índios, o fato de dois homens terem uma relação sexual não se constituía em problema. Tal fato era encarado com naturalidade.

Assim, a forma como cada grupo entende a sexualidade é diferente. Até mesmo a diferença entre homens e mulheres, que na nossa sociedade é baseada na presença ou ausência de pênis, e parece algo 'natural', não é feita dessa mesma forma em todos os grupos sociais.

Pierre Clastres (1988), antropólogo francês, estudando os índios Guaiaqui, do Paraguai, observou que para esses índios, homem é aquele que maneja o arco e mulher é a que carrega o cesto. Às mulheres é proibido tocar no arco e os homens são impedidos de manipularem o cesto. Existe um tabu maior no toque da mulher no arco. Para esses índios é muito mais grave o contato da mulher com o arco "que o do homem e do cesto. Se uma mulher pensasse em pegar um arco, ela atrairia, certamente, sobre seu proprietário o pané, quer dizer, o azar na caça, o que seria desastroso para a economia dos guaiaqui." (CLASTRES, 1988, p.75). 
Para os gauaiaqui, o arco é o símbolo da virilidade do homem e se este não consegue fazer uso desse artefato, perde o status de caçador/homem. Nas palavras de Clastres:

\begin{abstract}
sendo incapaz de preencher sua função de caçador, perde por isso mesmo a sua própria natureza e a sua substância lhe escapa: obrigado a abandonar um arco doravante inútil, não lhe resta senão renunciar à sua masculinidade e, trágico e resignado, encarrega-se de um cesto. A dura lei dos guaiaqui não lhe deixa alternativa. Os homens só existem como caçadores, e eles mantêm a certeza da sua maneira de ser preservado o seu arco do contato da mulher. Inversamente, se um indivíduo não consegue mais realizar-se como caçador, ele deixa ao mesmo tempo de ser um homem: passando do arco para o cesto, metaforicamente ele se torna uma mulher. (CLASTRES, 1988, p. 75-76)
\end{abstract}

Assim, quando um homem não tem habilidade com o arco ou é vítima do pane e para sobreviver precisa utilizar o cesto, vai ser visto como mulher e é cobrado dele que adote as posturas relativas ao feminino para ser aceito pela tribo. Clastres (1988) cita a história de dois índios que não possuíam habilidade com o arco e passaram a se utilizar do cesto. Cada um deles, porém, adotou uma forma diversa de enfrentar a situação. Um deles quando começou a utilizar o cesto, deixou o cabelo crescer e foi morar com as mulheres da tribo, sendo procurado sexualmente pelos homens. Nessas relações sexuais, esse índio adotou uma postura 'passiva', e para os Guaiaqui, esse índio era um kyrypymeno (ânus-fazer amor), o que estava em conformação com a sua inabilidade com o arco.

O outro índio, embora também não conseguisse caçar com o arco, não adotou o modo de vida feminino. Carregava o cesto de forma diversa das mulheres e ainda participava de alguns cânticos dos homens. Essa não adequação desse índio à sua condição de mulher, já que carregava o cesto, fez com que o mesmo sofresse o desprezo dos demais integrantes da tribo, afinal ele não se encaixava nem no círculo dos homens, pois não manejava o arco, nem no das mulheres. Ele "constituía por si mesmo uma espécie de escândalo lógico; não se situando em nenhum lugar nitidamente identificável, ele escapava do sistema e introduzia nele um fator de desordem: o anormal" (CLASTRES, 1988, p. 77).

Aqui, observa-se a necessidade de adequação dos indivíduos a um padrão que indica a forma como estes devem agir para serem aceitos 
no grupo. Os papéis sexuais são rigidamente definidos, e a identidade de gênero está atrelada a esses papéis.

Como fruto de uma construção humana, a sexualidade vai sofrer restrições, mesmo de formas diferentes, em todos os povos, conforme nos assinala Taylor (1997). De acordo com esse autor, sociedades distintas apresentam diferentes códigos de conduta sexual, porém em todas as sociedades existe um padrão a ser seguido e, consequentemente, existem transgressões.

Segundo Brannon (1999 apud SABBAG, 2008 p.19) os modelos de comportamentos e atitudes considerados característicos de cada sexo,

são definidos como estereótipos, que a princípio já estão
colocados socialmente antes do nascimento de cada indivíduo,
com função de diferenciar as atitudes sociais de homens e
mulheres. Os estereótipos consistem em crenças sobre
características bio-fisiológicas e plásticas de homens e
mulheres, como sendo atividades apropriadas para cada sexo.

Aqueles que apresentam comportamentos e atitudes diferentes do esperado, da 'norma', acabam sendo considerados homossexuais, mesmo que nem tenham ainda consciência do que isso significa.

A ideia de que a espécie humana englobaria homens e mulheres, ou seja, que existiriam sexos distintos é algo relativamente recente. Durante muitos séculos acreditou-se que havia um único sexo, o masculino. Dele derivaria o feminino - as mulheres apresentariam os mesmos órgãos sexuais que os homens, porém estes estariam dentro do corpo, e não externalizados, como no caso deles. (LAQUEUR, 2001)

Segundo esse autor, foi Galeno, médico grego que viveu no século II d.C.que desenvolveu a ideia de um só sexo. De acordo com Laqueur (2001), Galeno acreditava que por não terem recebido suficiente calor vital, as mulheres seriam "homens invertidos, logo menos perfeitas." (LAQUEUR, 2001, p. 42). Galeno faz uma comparação entre os olhos da toupeira e os genitais femininos:

os olhos da toupeira têm a mesma estrutura dos olhos de outros animais, só que a toupeira não enxerga. Seus olhos não abrem, 'não se projetam, mas continuam ali, imperfeitos'. A genitália da mulher também 'não abre' e permanece em uma visão imperfeita do que seria se fosse projetada para fora. (LAQUEUR, 2001, p. 43). 
Galeno, portanto, compreende as diferenças físicas entre homens e mulheres, porém atribui essas diferenças a uma ausência de calor, a uma não completude da transformação da mulher em homem, e não à existência de sexos distintos.

As concepções filosóficas e médicas gregas sobre a existência de um só sexo também encontram apoio no cristianismo. Tanto que a ideia de dois sexos só vai surgir no final do século XVIII, quando se passou a admitir que as mulheres fossem tão humanas quanto os homens. As diferenças entre homens e mulheres estariam não apenas no corpo, mas também na personalidade (VILLELA; ARILHA, 2003).

Foi a partir do final do século XVIII, quando começaram a ocorrer mudanças na realidade social, que a forma como o corpo feminino era entendido também sofreu alterações. Como nos diz Costa (1995, p.108) "a partir do momento em que uma outra ordem política foi imaginada, as diferenças entre mulheres e homens começaram a ser pensadas em termos de descontinuidade e oposição e não em termos de continuidade e hierarquia."

Nessa nova ordem, procurou-se justificar a diferença dos papéis femininos e masculinos a partir de uma matriz biológica. Mulheres seriam mais frágeis, portanto necessitariam ser protegidas das agruras do mundo pelos homens. A eles caberiam os papéis de vida pública, e a elas ficariam reservados os da vida privada, dentro do lar, afinal "nem todos podem ser cidadãos ao mesmo título que o homem. Alguns devem ser preservados da dureza do mundo. As mulheres e as crianças vão ser estes elementos protegidos pela vida privada" (COSTA, 1995, p.113)

Passaram a existir fronteiras bem demarcadas para cada sexo, para os homens a esfera de ação seria o domínio público, para as mulheres o privado. Também o comportamento, as emoções, vão ser associados a um ou outro sexo - as mulheres seriam mais sensíveis, propensas ao choro, muito emotivas; os homens mais duros, sem choros ou comoções. Formas de andar, falar e trajar são tidos como característicos de cada sexo.

Associou-se gênero a sexo, como se a presença de um determinasse a existência do outro. Giddens (1993, p. 216), citando Devor (1989), indica que 
as atribuições do gênero eram determinadas da seguinte maneira:

1 - Tomava-se como certo que todo indivíduo era homem ou mulher, sem ninguém 'no meio'.

2 - As características físicas e os traços de comportamento dos indivíduos eram interpretados como masculinos ou femininos, segundo um esquema de gênero dominante.

3 - Os papéis dos gêneros eram rotineiramente ponderados e estabelecidos, dentro dos limites dos padrões permissíveis das situações dos gêneros.

4 - As diferenças entre os gêneros assim constituídas e reconstituídas eram destinadas a concretizar as identidades sexuais, purificando-se os elementos de 'gênero cruzado'.

5 - Os protagonistas controlavam o seu próprio desempenho e comportamento, de acordo com a identidade sexual 'naturalmente concedida'.

Existe assim uma só forma de ser homem ou mulher. E as pessoas devem conformar sua forma de agir de acordo com o que dita seu sexo biológico. Existe uma 'naturalização' desses papéis sexuais, como se eles fossem fixos, imutáveis. $O$ esquema de gênero distinguia claramente os homens das mulheres não só pelas características físicas, mas também pelo comportamento que estes deveriam 'naturalmente' apresentar. Afinal, se as mulheres têm a função biológica de cuidar da prole, esse tipo de cuidado exige um comportamento tranquilo, protetor, carinhoso. As emoções lhe caem bem, ela deve ter amor por seus filhos, deve ser cuidadosa. O homem, por sua vez, obrigado a enfrentar o ambiente externo, hostil, deve ser duro, e não pode mostrar as emoções (coisas femininas). Confundir os comportamentos seria assim, ir contra a natureza biológica.

Dessa forma, ser homem ou mulher, no modelo dos dois sexos, diferia fundamentalmente do modelo de sexo único. Homens e mulheres no modelo dos dois sexos são considerados 'opostos', tanto na genitália quanto nos comportamentos - diametralmente opostos. No modelo do sexo único essa oposição não existia. Mulheres e homens eram reconhecidos como pertencentes a um só modelo, portanto não seriam opostos, apenas um constituía o inverso do outro.

Apenas quando ocorre a mudança na forma de conceber as diferenças entre homens e mulheres, bem como no surgimento de uma fixidez na associação entre o sexo biológico com gênero e papéis sexuais, é que 
passa a existir um ambiente propício para o surgimento da figura do homossexual. Embora não fosse novidade o desejo entre indivíduos do mesmo sexo biológico, a categoria 'homossexual' ainda não existia.

Só quando os sexos foram considerados 'naturalmente' distintos, e os papéis atribuídos a cada um deles foram rigidamente delimitados, é que surge a figura do homossexual. Ele era o que não se 'encaixava' aos padrões considerados 'naturais', normais para cada gênero. Dessa forma,

nessa separação dos gêneros, o homossexual surge como o homem invertido e sua inversão vai ser classificada como perversão e como antinatural. Perversão porque a inversão significava, como já foi dito anteriormente, ter o corpo de homem com a sexualidade feminina. Segundo o discurso médico, o homossexual apresentava um 'desvio' duplo: sua sensibilidade nervosa e seu prazer sexual eram femininos. (FERRARI, 2004, p. 41)

Ou seja, aquele homossexual masculino, que não se encaixa no modelo que é imposto a todos os que apresentam o mesmo sexo biológico que o seu, será visto como um doente, pois vai de encontro à natureza. Desse modo, com o surgimento do modelo dos dois sexos, ocorreu uma mudança significativa na forma como eram vistos os homoeróticos.

No one-sex model a mulher era um homem invertido e inferior. Mas sua qualidade metafísica era conforme a natureza. O sexo da mulher, com sua especificidade calórica, era um requisito necessário à reprodução da vida e da espécie humana. A inversão designava apenas 'inversão anatômica dos órgãos' e não torção ou distorção da natureza sexual feminina. No twosex model a mulher passa a inverso complementar do homem e isto ainda será considerado natural. Em contrapartida, a nova imagem da inversão vai colar-se ao homem, porém com um adendo: o invertido será o homossexual e sua inversão será vista como perversão, porquanto antinatural. Diante da bisexualidade político-científica, a mulher persistia sendo inferior, mas sempre dentro da norma natural; o homossexual, não. Sua inversão será perversão porque seu corpo invertido apresenta um duplo desvio: sua sensibilidade nervosa e seu prazer sensual eram femininos. [...] Desde então, a feminilidade do homossexual vai ser afirmada, a despeito de qualquer contraexemplo empírico ou de qualquer incongruência conceitual. Ele tinha que 'ser feminino', pois, não sendo feminino, não tinha como ser 'invertido'. (COSTA, 1996, p.85-86).

A figura do homossexual surge, então, como aquele que não se encaixa na lógica do modelo rígido dos dois sexos. Não se comporta como o 
esperado para seu sexo biológico. No caso dos homens, são considerados homossexuais aqueles que têm atitudes consideradas femininas, sendo delicados e sensíveis.

Identificamos aqui a forma estereotipada do homossexual: indivíduo efeminado que quer ser mulher. Como assinala Amaral (1998), é a partir da relação que se tem com o estereótipo, e não com a pessoa, que ocorre a concretização do preconceito.

O preconceito contra aquele que ousa divergir da norma é forte. A homofobia, a aversão ao diferente é tanta que se chega ao ponto de matar. Atitudes homofóbicas vão desde xingamentos ao assassinato. Como nos dizem Mott e Cerqueira (2003), no livro 'Matei porque odeio gay', as atitudes homofóbicas “incluem violência física, golpes e tortura, culminando em violentíssimos e pavorosos assassinatos - via de regra cometidos com revoltantes requintes de crueldade, abrangendo elevado número de golpes e tiros, o uso de múltiplos instrumentos e tortura prévia” (MOTT; CERQUEIRA, 2003, p.8).

Na escola, embora a homofobia não mate, pode deixar traumas e dores que acompanharão o(a) jovem para o resto da vida. Alunos e alunas têm seus comportamentos questionados, reprovados ou reforçados. Comportamentos considerados como 'adequados' são reforçados por professores, funcionários e colegas, já os entendidos como 'não corretos' sofrem a exprobração e o repúdio. A escola concentra assim, esforços para reproduzir o padrão de sexualidade considerado 'normal' nos seus alunos. Aos que não se encaixam nesse padrão, os 'excêntricos', são reservadas 'as marcas da particularidade, da diversidade e da instabilidade" (LOURO, 2005, p. 44). Essas marcas são apontadas, colocadas em evidência, e os alunos ficam expostos às diversas formas de agressão, pelo simples fato de serem diferentes da norma. Se, como Reich (1977, p.248) diz, "a homossexualidade não é crime social, não prejudica ninguém”, por que tanta aversão e agressividade contra aqueles que transgridem as normas de gênero? E por que a escola, que deveria ser um ambiente de promoção da tolerância, permite que tais violências ocorram?

Segundo Castro, Abramovay e Silva (2004) quando a homossexualidade é tratada de forma preconceituosa e discriminatória no ambiente escolar, pode levar o(a) aluno(a) ao abandono da escola, à interrupção da carreira, pois ele(a) pode sentir falta de pertencimento a 
esse lugar. Estas autoras ressaltam ainda que existe uma tendência dos professores(as) em banalizar as atitudes discriminatórias contra esses alunos, pois "consideram que as brincadeiras não são manifestações de agressão, naturalizando e banalizando as expressões de preconceitos" (p.289).

\section{Análise dos resultados}

Nesse sentido, com o intuito de identificar se o Professor e as Professoras participantes dessa pesquisa acreditam ser possível identificar tendências homossexuais em alunos, foi proposta a seguinte questão: "Você acredita que é possível identificar tendências homossexuais em alunos? Caso a resposta seja afirmativa, como essa identificação poderia ser feita?"

Os nove professores(as) pesquisados, apenas três assinalaram não ser possível fazer a identificação de tendências homossexuais em alunos. Um professor assinalou as duas alternativas (Sim e Não), sem explicitar o que queria dizer com essa dupla marcação. Esse professor provavelmente compreende que a idéia de que os indícios que se acredita serem característicos de homossexuais não se configuram obrigatoriamente verdadeiros, no entanto ainda se vale desse estereótipo para 'visualizar' o homossexual. Para cinco respondentes essa identificação pode ser feita. (Quadro 1).

Quadro 1 - Consideram ser possível identificar tendências homossexuais em alunos

\begin{tabular}{|c|c|}
\hline & Professor/ Professoras \\
\hline SIM & P.1; P.3; P.4; P.5; P.6; P.7 \\
\hline N $\tilde{A} \boldsymbol{O}$ & P.2; P.3; P.8; P.9 \\
\hline
\end{tabular}


Entre os cinco professores que assinalaram ser possível realizar tal identificação, um não explicitou como poderia ser feita e quatro descreveram como a identificação destas tendências poderia ser feita da seguinte forma:

“Através de preferências, atitudes, pontos de vista." (P.1)

"Modo de falar, andar, trajar" (P.4).

Vale-se assim de padrões baseados no que é culturalmente aceito como pertencente a um ou outro sexo. A homossexualidade é confundida com formas de agir, que são reconhecidas como pertencentes a um ou outro sexo por convenção social. A delicadeza nos gestos, por exemplo, que é considerada atributo feminino, segundo depoimento colhido por Trevisan (1986) é muito comum entre homens da tribo Kraô, do estado de Goiás. Como indica Louro (2008) determinadas atitudes só fazem sentido dentro do contexto em que são produzidas.

Dois professores mesmo assinalando ser possível fazer a identificação, ressaltaram que nem sempre tais indícios funcionam.

"Mesmo respondendo 'sim', acredito na dificuldade dessa identificação. Normalmente nos valemos doa gestos efeminados (meninos) ou masculinizados (meninas), mas nem sempre essa regra é válida.” (P.7)

Essas respostas assinalam que estes professores valem-se da imagem estereotipada do homossexual, como sendo aquele que é efeminado, conforme indica Costa (1996). Identificar um aluno como homossexual, por qualquer característica que se acredite ser alusivo a tal orientação sexual, é uma forma de reforçar o estereótipo e aponta a existência de um padrão de comportamento masculino que difere daquele que seria um feminino. Confunde-se orientação sexual - que está relacionado ao desejo - com papéis sexuais, que são estabelecidos por convenção social.

Os Parâmetros Curriculares Nacionais (PCN) ressaltam a associação entre certos comportamentos e a orientação sexual, quando dizem que:

Muitas vezes se atribui conotação homossexual a um comportamento ou atitude que é expressão menos convencional de uma forma de ser homem ou mulher. Ela escapa aos 
estereótipos de gênero, tal como um menino mais delicado ou sensível ser chamado de 'bicha' ou uma menina mais agressiva ser vista como lésbica, atitudes essas discriminatórias (BRASIL, 1998, p.325).

Essa relação que é feita entre a atipicidade de gênero (a apresentação de certos comportamentos que são vistos como característicos do outro gênero) com a orientação do desejo não reflete a realidade, pois como adverte Picazio (1998) não existe correlação entre os papéis sexuais e a orientação sexual.

As demarcações entre as fronteiras do que são 'coisas de meninos' e 'coisas de meninas' são bem delimitadas. Aqueles que procuram ultrapassar essa fronteira, que acreditam ser possível ser homem de outra forma, rompendo com aquilo que Pollack (1999) chamou de "camisa de força sexual" (p.433) se permitindo serem "ao mesmo tempo duros e gentis, vulneráveis e corajosos, dependentes e independentes." (POLLACK, 1999, p.439) sofrem recriminações de toda a sorte, independente de sua orientação sexual.

Um educador que reforce essa forma estereotipada de pensar a homossexualidade está validando o modelo único de ser homem ou mulher. Dessa forma, o aluno heterossexual que não se encaixe no comportamento padrão admitido para seu sexo biológico, também vai se sentir, de forma similar aos homossexuais, um 'desviante'. Ao romper com a norma de gênero, transitando entre o comportamento aceito tanto para masculino quanto para feminino, ele questiona a fixidez atribuída aos papéis sexuais. De modo semelhante ao índio observado por Clastres (1988), que não aceitava desempenhar um papel feminino apenas por não manejar o arco, esse aluno vai se constituir, naquilo que esse antropólogo denominou de "uma espécie de escândalo lógico" (CLASTRES,1988, p.77). Dessa forma, não é apenas a homossexualidade que vai ser 'mal vista'. Aquele ou aquela que não apresentar determinados comportamentos considerados típicos para seu sexo é igualmente discriminado.

\section{Considerações finais}

A forma como professores e professoras de Ciências lidam com a sexualidade servirá de referência para seus alunos. Neste trabalho, 
evidenciamos que a maior parte do grupo pesquisado (seis dos nove professores) acredita ser possível identificar tendências homossexuais em alunos. Este fato aponta que para esses educadores (as) existem comportamentos próprios 'para menino' e 'para menina'. Aqueles alunos que apresentam outra forma de se comportar vão ser identificados como homossexuais. Tal atitude reforça a discriminação e contribui para a manutenção do modelo comportamental vigente.

É imprescindível desconstruir essa relação fixa existente entre sexo biológico e papéis sexuais para que os alunos possam vivenciar plenamente as expressões da sexualidade. Dessa forma, possibilitaria que meninos e meninas se sentissem livres para expressar seus sentimentos e formas de agir livremente, sem que corressem o risco de serem mal visto ou mesmo agredidos. Precisamos desengessar os comportamentos, assumindo que não existe uma única forma de ser homem ou mulher, mas várias, e todas elas válidas.

\section{Referências}

AMARAL, Lígia Assumpção. Sobre crocodilos e avestruzes: falando de diferenças físicas, preconceitos e sua superação. In: AQUINO, Julio Groppa. Diferenças e preconceito na escola: alternativas teóricas e práticas. São Paulo: Summus, 1998.

BRASIL. Secretaria de Educação Fundamental. Parâmetros curriculares nacionais: terceiro e quarto ciclos: temas transversais. Secretaria de Educação Fundamental. - Brasília: MEC/SEF, 1998.

CALDAS-COULTHARD, Carmen Rosa ; VAN LEEUWEN, Theo. Discurso crítico e gênero no mundo infantil: brinquedos e a representação de atores sociais. Linguagem em (Dis)curso, Tubarão. SC, v. 1, n. 1, 2000.

CARDOSO, M. Elas venceram. Revista Veja, São Paulo, n.1645, p.20-2, $2000 \quad$ Disponível em <http://veja.abril.com.br/190400/p_072.html> Acesso em 14 ago 2009. 
CASTRO, Mary Garcia; ABRAMOVAY, Miriam; SILVA, Lorena Bernadete da. Juventudes e sexualidade. Brasília: UNESCO. Brasil, 2004. 426p.

CLASTRES, Pierre. $\mathrm{O}$ arco e o cesto. In: A Sociedade contra

o Estado. Rio de Janeiro: Francisco Alves, 1988. p.71-89.

CONFEDERAÇÃO NACIONAL DOS TRABALHADORES EM EDUCAÇÃO. A diversidade ensina e não é um problema. Brasília: CNTE, 2008. Disponível em: $<$ http://www.cnte.org.br/index.php?option=com_content\&task=view $\& \mathrm{id}=573 \&$ Itemid=82 > . Acesso em: 27 out. 2008.

COSTA, Leda M. da. Maria-chuteiras x torcedoras "autênticas". Identidade feminina e futebol. "USOS DO PASSADO' XII ENCONTRO REGIONAL DE HISTÓRIA ANPUH-RJ, 2006, Niterói. Anais do XII Encontro Regional de História ANPUH-RJ, Niterói: Universidade Federal Fluminense, 2006, p. 1-11

COSTA, Jurandir Freire. A face e o verso: estudos sobre homoerotismo II. São Paulo: Escuta, 1995.

O referente da identidade sexual. In: PARKER, Richard; BARBOSA, Regina Maria (orgs). Sexualidades Brasileiras. Rio de Janeiro: Relume Dumará: ABIA: IMS/UERJ, 1996.p. 63-89.

CRUZ, Maria Helena Santana. Trabalho, Gênero, Cidadania: Tradição e Modernidade. $1^{a}$ ed. São Cristóvão: Editora UFS, Aracaju: Fundação Oviêdo Teixeira, 390p. 2005a.

Mudanças tecnológicas e relações de trabalho: um olhar de gênero na indústria têxtil. In: Revista da Fapese de Pesquisa e Extensão, v. 2, p. 7-24, jul./dez. 2005b. Disponível em: <www.fapese.org.br/revista_fapese/v1n2-2005/artigo_1.pdf>. Acesso em: 10 jan. 2009.

EL-HANI, Charbel Niño. O Insustentável Peso dos Genes: a persistência do determinismo genético na mídia e na literatura científica. Salvador. Dissertação (Mestrado em Educação) Faculdade de Educação da Universidade Federal da Bahia, 1995. 
FERRARI, Anderson. Quem Sou Eu? Que Lugar Ocupo? Grupos Gays, Educação e a Construção do Sujeito Homossexual. Tese (Doutorado em Educação). UNICAMP - Universidade Estadual de Campinas. Faculdade de Educação, 2004.

FINCO, Daniela. Relações de gênero nas brincadeiras de meninos e meninas na Educação Infantil. Pro-Posições: Dossiê: Educação Infantil e Gênero, v. 14, n. 42, 2003, p.89-102.

FORASTIERI, Valter. Concepções de Professores de Biologia do Ensino médio sobre a variedade de Orientações sexuais (Dissertação de Mestrado) Universidade Federal da Bahia. Mestrado em Ensino de Ciências, 2004.

FRANZINI, Fábio. Futebol é "coisa para macho"?: Pequeno esboço para uma história das mulheres no país do futebol. Revista Brasileira de História, São Paulo, v. 25, n. 50, dez. 2005. Disponível em < http://www.scielo.br/scielo.php?pid=S0102-

01882005000200012\&script=sci_arttext\#back1> Acesso em 16 ago 2009.

FREIRE, Paulo. Pedagogia do oprimido. $17^{\text {a }}$ ed. Rio de Janeiro: Paz e Terra; 1987.

FURLANI, Jimena. Mitos e Tabus da Sexualidade Humana: subsídios ao trabalho em educação sexual. $2^{\mathrm{a}}$ ed. Belo Horizonte: Autêntica, 2003.

GIDDENS, Anthony. A transformação da intimidade: sexualidade, amor e erotismo nas sociedades. São Paulo: UNESP, 1993.

LAQUEUR, Thomas Walter. Inventando o sexo: corpo e gênero dos gregos a Freud. Rio de Janeiro: Relume Dumará, 2001.

GOELLNER, Silvana. A produção cultural do corpo. In: LOURO, Guacira; NECKEL, Jane; GOELLNER, Silvana(Orgs.) Corpo, gênero e sexualidade: um debate contemporâneo na educação. Petrópolis: Vozes, 2003. p. 28-40. 
LAQUEUR, Thomas Walter. Inventando o sexo: corpo e gênero dos gregos a Freud. Tradução Vera Whately. Rio de Janeiro: Relume Dumará, 2001.

LOURO, Guacira Lopes. Pedagogias da Sexualidade. In: $\mathbf{O}$ Corpo educado: pedagogias da sexualidade. $2^{\mathrm{a}}$ ed. Belo Horizonte: Autêntica, 2001. p. 7-34.

. Currículo, gênero e sexualidade: O "normal", o "diferente" e o "excêntrico". In: V; FELIPE, Jane; GOELLNER, Silvana Vilodre. Corpo, Gênero e Sexualidade: Um debate contemporâneo na educação. Petrópolis: Vozes, 2005. p. 41-52.

. Um corpo estranho. Ensaios sobre sexualidade e teoria queer. Belo Horizonte: Autêntica Editora, 2008.

MINAYO, Cecília de Souza. Pesquisa Social: teoria, método e criatividade. Petrópolis, RJ: Vozes, 2007.

MONTESQUIEU, Charles de Secondart. Cartas Persas. São Paulo: Perosa, 1991.

MOTT, Luiz. Os gays e os homens delicados. [sd] Disponível em: <http://br.geocities.com/luizmottbr/cronica2.html>. Acesso em: 19 jul. 2008.

MOTT, Luiz; CERQUEIRA, Marcelo. Matei porque odeio Gay. Salvador: Editora Grupo Gay da Bahia, 2003.

NEGRINI, Tiago de F. Iconografia da Moda Masculina. Trabalho de Conclusão de Curso (Bacharel em Moda), Centro Universitário Salesiano, São Paulo, 2006.

PAECHTER, Carrie. Meninos e meninas: aprendendo sobre masculinidades e feminidades / Carrie Paechter; tradução, consultoria e supervisão Rita Terezinha Schimidt. Porto Alegre: Artmed, 2009. $192 p$.

PICAZIO, Cláudio. Sexo Secreto: temas polêmicos da sexualidade. São Paulo: Summus, 1998. 
POLLACK, William. Meninos de verdade: conflitos e desafios na educação de filhos homens. São Paulo:Alegro, 1999.

REICH, Wilhelm. A Revolução Sexual. São Paulo: Zahar,1977.

RUELA, Beatriz; ZACURA, Sofia F.; ASSARITI, Dolores S.; MORAES, Júlio P. de; SANTOS, Lauren A. de S. O curso de formação em Campinas. In: RIBEIRO, Cláudia M. (Org.). Tecendo gênero e diversidade sexual nos currículos de educação infantil. Lavras: UFLA, 2012.p. 47-57.

SABBAG, Samantha. Percepção dos Estereótipos de Gênero na Avaliação do Desenvolvimento Motor de Meninos e Meninas. Dissertação (Mestrado em Ciências do Movimento Humano) Universidade do Estado de Santa Catarina. 2008.

SARAT, Magda; CAMPOS, Míria Izabel. Memórias de infância e identidade de gênero na formação das profissionais na educação infantil. In: Fazendo Gênero 8: Corpo, Violência e Poder, 2008, Florianópolis. Anais... Disponível em http://www.fazendogenero.ufsc.br/8/sts/ST10/Sarat-Campos_10.pdf Acesso em: 22 set. 2013.

SOUZA, Fabrício de; RODRIGUES, Maria Margarida Pereira. A segregação sexual na interação de crianças de 8 e 9 anos. Psicologia: Reflexão e Crítica., Porto Alegre , v. 15, n. 3, 2002 . Disponível em < http://www.scielo.br/scielo.php?pid=S010279722002000300004\&script=sci_arttext >. Acesso em 03 nov. 2013

SULLIVAN, Andrew. Praticamente normal: uma discussão sobre o homossexualismo. São Paulo: Companhia das Letras, 1996.

TAMANAHA, Nádia. Não sou gay! In: AthosGLS Notícias [on line]. 19 set. $2008 . \quad$ Disponível em:< http://www.athosgls.com.br/noticias_visualiza.php?contcod=24618> Acesso em: 14 out 2008.

TAYLOR, Timothy. A Pré-História do Sexo: quatro milhões de anos de cultura sexual. Rio de Janeiro: Campus, 1997. 
TREVISAN, João Silvério. Devassos no paraíso. São Paulo: Max Limonad, 1986.

VILLELA, Wilza V.; ARILHA, Margareth. Sexualidade, gênero e direitos sexuais e reprodutivos. In: BERQUÓ, Elza (org.) Sexo \& vida: panorama da saúde reprodutiva no Brasil. Campinas, SP: Editora da Unicamp, 2003, p. 95-150. 